We next determined the mercury in a sample of cinnabar by distilling the latter with lime, collecting and weighing the metal as directed in Fresenius' Quantitative Analysis, Am. Ed., p. 306.

I. 0.9590 gram of mineral gave 0.8 I 94 gram of metal, or 85.44 per cent.

2. 0.8586 gram of mineral gave 0.7325 gram of mercury, or 85.31 per cent.

Portions of the same mineral were weighed out in platinum dishes and after solution in twenty to twenty-five cc. of sodium sulphide of specific gravity previously mentioned, were diluted with water to $25 \mathrm{cc}$. and electrolyzed at a temperature of $70^{\circ}$, with a current of N. D $200=0.12$ ampere. The period of time allowed for the precipitations never exceeded three hours. The results were :

\begin{tabular}{|c|c|c|}
\hline $\begin{array}{c}\text { Cinnabar. } \\
\text { gram. }\end{array}$ & $\begin{array}{l}\text { Mercury. } \\
\text { gram. }\end{array}$ & Petcentage. \\
\hline 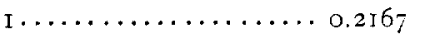 & 0.1850 & 85.37 \\
\hline $2 \ldots \ldots \ldots \ldots \ldots \ldots, 0.2074$ & 0.1769 & 85.29 \\
\hline $3 \ldots \ldots \ldots \ldots \ldots \ldots \ldots 0.2432$ & 0.2077 & 85.40 \\
\hline
\end{tabular}

We would observe that during the electrolytic decomposition the platinum dishes should be carefully covered to prevent evaporation, thereby exposing a rim of metal, which if not in part volatilized, would yet be changed to mercury sulphide. The latter is indicated by a dark-colored film. With a little attention there should be no question as to the final outcome of any determination made in this way. We regard the method as entirely satisfactory. The short time required for a determination, as outlined above, will recommend it in our judgment to analysts generally.

UnIVersity of Pennsylvania.

\title{
THE PRECIPITATION OF PHOSPHOMOLYBDATE IN STEEL ANALYSIS.
}

BY GEORGE AUCHY.

Received December 2, 7895 .

I a recent paper ${ }^{1}$ Messrs. Blair and Whitfield give a new formula for the preparation of molybdate solution, which is a great improvement on the old one, as by its use the separation of

1 this Journal, $17,74 \bar{i}$. 
amnonium molybdate from the solution by long standing is avoided and the solution retains its strength. In using solution of the new formula, however, the writer, a number of times, has had a further precipitation of phosphomolybdate to occur after filtration. This additional precipitate could not have resulted from insufficiency of molybdate solution-sixty to seventy-five cc. of the solution having been used; nor from insufficient shaking-ten minutes having been given in each case. The precipitation seemed to be the result of the dilution of the liquid by the wash water, and not of the longer standing, as in several cases the original phosphomolybdate precipitate had stood an hour or more, and in one case, all night before filtering. This seemed an indication that dilute solution is a help to complete precipitation. But the query then arose, Why had this after separation of phosphomolybdate never occurred before in using molybdate solution of the old formula? The explanation at oncesuggested itself. Because when solution of the old formula is used the amount of ammonium nitrate present is necessarily much larger. If these assumptions are correct, it then would seem that the presence of ammonium nitrate and a dilute solution are both important factors in the thorough precipitation of the phosphomolybdate (the former is, indeed, a well known fact). Acting upon this hint, precipitations have since then taken place in solutions of larger volume, and containing a greater proportion of ammonium nitrate; effected by increasing the volume of nitric acid (sp. gr. I.I3, recommended by Drown), as used for solution of two grams steel, to Ioo cc., and the amount of strong ammonia used for neutralization, to fifteen cc. diluted with fifty cc. cold water. The following few experiments which the writer has had time to make, give some corroboration to this theory.

Experiment 5 . Heat 369. I. Solution nearly neutral. Volume small. Considerable ammonium nitrate present. Sixty cc. nitric acid (I.I3) for solution of the steel. Eight cc. strong ammonia for neutralization. Thirty-five cc. molybdate solution of old formula, -0.009 per cent.

2. Solution very strongly acid. Dilute in volume. Largeexcess of ammonium nitrate present. One hundred cc. nitric acid (I.r3) for solution. Fifteen cc. strong ammonia for neu- 
tralization. Then fifty $\mathrm{cc}$. strong nitric acid, and fifteen to twenty grams of crystallized ammonium nitrate. Sixty cc. of molybdate, new formula, $\rightarrow$-oro per cent.

Experiment 2. Heat 352. I. Solution nearly netutral. Volume dilute. Considerable ammonium nitrate present. One hundred cc. nitric acid (I.I3) for solution. Fifteen $\mathrm{cc}$. strong ammonia for neutralization. Sixty $c c$. molybdate solution of new formula, $\longrightarrow$-.I6I per cent.

2. Solution very strongly acid. Volume dilute. Large excess of ammonium nitrate present. One hundred $c c$. nitric acid (I.I3) for solution. Fifteen cc. strong ammonia for neutralization. Then fifty cc. strong nitric acid, and fifteen to twenty grams of crystallized ammonium nitrate. Sixty cc. molybdate solution of new formula, $\longrightarrow$ - I 60 per cent.

These results tend to show that rather large dilution and plenty of ammonium nitrate are important conditions in the complete precipitation of the phosphomolybdate, and that the degree of neutralization of the nitric acid before precipitation is unimportant, the complete precipitation depending, not upon the approximate neutralization of the liquid, but upon the amount of ammonium nitrate present and the dilution of the solution. The reverse of this (solution small in bulk and nearly neutral) is sometimes recommended.' As before stated, about the right dilution and the proper amount of ammonium nitrate seems to be obtained by using one hundred $c c$. nitric acid of specific gravity I. I 3 for solution of the steel, and fifteencc. strong ammonia in fifty cc. cold water for neutralization previous to the addition of the molybdate solution. But if it be desired to have the solution less in volume, this amount of ammonium nitrate will not always suffice, as the writer has found by experience. The dilution seems to be an important requisite when molybdate of the new formula is used.

The amount of phosphorus precipitating after filtration, in the cases referred to (determined as pyrophosphate to guard against the contingency of the separation being ammonium molybdate merely), was respectively $0.026,0.003$, and 0.013 per cent.

As showing the very great degree of error that may occur 1 This Journal, 17 . I3I. 
from the careless use of molybdate solution of the old formula, the following results may be of interest to members of the society.

The molybdate solution had been made up for two-possibly three or four weeks. Then a close-down of the works for three weeks for repairs, at the end of which time the use of the solution was thoughtlessly resumed. But the extreme lowness of the results for heats 307 and 308 threw suspicion upon the solution, and duplicate determinations were made with fresh solution and continued till complete demonstration was had that the moly date solution was at fault.

\begin{tabular}{|c|c|c|}
\hline & $\begin{array}{l}\text { With old solution. } \\
\text { Per cent. }\end{array}$ & $\begin{array}{l}\text { With fresh solution. } \\
\text { Per cent. }\end{array}$ \\
\hline Heat & $306 \ldots \ldots \ldots \ldots \ldots \ldots \ldots, 0.048$ & 0.060 \\
\hline " & $307 \ldots \ldots \ldots \ldots \ldots \ldots \ldots \ldots \ldots \ldots+0.004$ & 0.006 \\
\hline " & 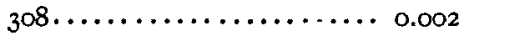 & 0.006 \\
\hline " & $309 \ldots \ldots \ldots \ldots \ldots \ldots \ldots \ldots \ldots \ldots$ & 0.035 \\
\hline$"$ & $310 \ldots \ldots \ldots \ldots \ldots \ldots \ldots \ldots \ldots \ldots$ o.or $_{3}$ & 0.020 \\
\hline "، & $311 \ldots \ldots \ldots \ldots \ldots \ldots \ldots, 0.002$ & 0.007 \\
\hline " & $312 \ldots \ldots \ldots \ldots \ldots \ldots \ldots \ldots, 0.002$ & 0.006 \\
\hline " & $313 \ldots \ldots \ldots \ldots \ldots \ldots \ldots \ldots \ldots \ldots+0.001$ & 0.008 \\
\hline " & $314 \ldots \ldots \ldots \ldots \ldots \ldots \ldots \ldots, 0.012$ & 0.036 \\
\hline " & $3{ }^{5} \ldots \ldots \ldots \ldots \ldots \ldots \ldots \ldots \ldots$ o.010 & 0.049 \\
\hline “ & $316 \ldots \ldots \ldots \ldots \ldots \ldots \ldots \ldots, 0.001$ & 0.007 \\
\hline " & $317 \ldots \ldots \ldots \ldots \ldots \ldots \ldots, 0.008$ & 0.049 \\
\hline " & $318 \ldots \ldots \ldots \ldots \ldots \ldots \ldots \ldots, 0.002$ & 0.020 \\
\hline
\end{tabular}

Many authorities advocate the taking of the temperature of the liquid before the addition of the molybdate solution; or the precipitation of the phosphomolybdate at a certain exact temperature $-85^{\circ}$ usually. The writer ventures to question whether, in a busy iron or steel works laboratory, it is worth while to take this trouble. For if five minutes be allowed for cooling after the solution is withdrawn from the flame, or if the flask be plunged into cold water a couple of times, there is no danger of its temperature being over $85^{\circ}$; and Babbitt has shown that down to $25^{\circ}$ all the phosphorus precipitates. Doolittle habitually precipitates at $35^{\circ}$ to evade arsenic. Another authority (Johnson, I think) avoids a temperature higher than $50^{\circ}$ to prevent oxides of iron and alumina from precipitating with the phosphomolybdate. So that where arsenic is not present any temperature 
between the wide limits of $25^{\circ}$ and $85^{\circ}$ is all right, and one can not err in omitting the use of the thermometer altogether. The iron is not likely to precipitate if the solution be acid enough. Nevertheless a temperature below $50^{\circ}$ is perhaps better than one higher.

As a reducing agent, perhaps the majority of chemists follow Jones in favoring ferrous sulphate. The writer found considerable phosphorus ${ }^{1}$ in a lot of nice clean looking sulphate labelled "Free from phosphorus," and has since then used sugar as originally recommended by Dr. Drown. The queerest experience in the way of impure chemicals was the finding of phosphorus in "C. P" nitric acid-enough to add 0.06 per cent. to the real percentage in the steel. A second bottle from the same makers also contained it, though not in so great amount.

\section{THE USE OF THE CALORIMETER IN DETECTING ADUL- TERATIONS OF BUTTER AND LARD. ${ }^{2}$}

BY F, A. DE SCHWEINITZ AND JAMES A, EMERY, Received Tantary 3,18096

WHILE engaged in a study of the comparative value of butters and oleomargarines, it occurred to one of us that possibly the determinations of their respective heats of combustion might be useful if taken in connection with other data. Prof. Atwater, who has for some time been conducting experiments with an improved calorimeter, very kindly consented to burn such samples as might be sent to him. The first results were so interesting that it occurred to us at once that this method might be useful in detecting the adulteration of butter with oleomargarine, and also perhaps in distinguishing between lards of different sources and compound lards. Accordingly, some specially selected samples of which duplicates were kept in our laboratory, were sent to Prof. Atwater, and in the case of the butters and oleomargarines the results confirmed our first suppositions. In the use of the lards, however, the results were not so sharply distinctive, but taken in conjunction with other analytical data will prove, as we will endeavor to show,

1 Not enough, however, to affect the results very seriously. o.II per cent. instead of 0.105 per cent., for instance; and 0.056 and 0.054 per cent. in another steel.

2 Read at the Cleveland meeting, Dec. 3r, 1895 . 